\title{
PASADO Y FUTURO DE LA OBRA CIENTÍFICA DE RÍO HORTEGA
}

\author{
Cesar Aguirre Viami \\ Catedrático de Histologia y Anatomia Patológica de la Universidad de Valladolid
}

ABSTRACT The article summarizes the biography of Pio del Rio Hortega , the geneses of his scientific works, and his relationship with Nicolás Achúcarro and Santiago Ramón y Cajal.

KEY WORDS Pio del Río Hortega biography. Nervous system Hystology. Pathological Anatomy. Nicolás Achúcarro. Santiago Ramón y Cajal.
RESUMEN El artículo realiza un recorrido de la biografía de Pío del Río Hortega y de la génesis de su obra científica, así como de su relación con Nicolás Achúcarro y Santiago Ramón y Cajal.

PALABRAS CLAVE Pío del Río Hortega, biografía. Histología del sistema nervioso. Anatomía patológica. Nicolás Achúcarro. Santiago Ramón y Cajal.
Nació don Pío en Portillo, villa de la provincia de Valladolid. Su primera infancia transcurre aquí, podemos suponer que muchas veces sus juegos infantiles se desarrollarían en el castillo y es fácil también, imaginar que sus aventuras tuvieran una tonalidad calleresca. Permanece en esta villa hasta que su padre decide en el traslado a la capital para que alli sus hijos puedan cursar sus estudios de bachiller.

Sus estudios de bachiller no permiten destacar en el curriculum del joven Pío ninguna nota sobresaliente. Únicamente destaca su afición con todo lo relacionado con la naturaleza.

Acabado el bachillerato se plantea la elección de la carrera universitaria. Don Pío se decide por cursar la de Medicina. Junta a sus apetencias por los problemas biológicos es claro que también le obligan a elegir esta carrera las posibilidades económicas de la familia que no puede permitirse el mantenerle fuera del ámbito familiar.

Lo mismo que sucedió en el bachillerato las notas que Pío obtiene en lo largo de la carrera de Medicina sólo refuerzan su interés por aquellas ciencias más ligadas el conocimiento biológico, mientras que las referidas al conocimiento clinico suscitan una menor atención lo que se refleja en calificaciones menos importantes.

A lo largo de su estancia en la Facultad de Medicina sólo va destacar por su capacidad para el dibujo lo que hace que sea llamado por el profesor de Anatomía Humana, don Leonardo de la Peña, para que ilustre sus clases con los excelentes dibujos que es capaz de realizar. Un profesor de la cátedra, su intimo Ramón López Prieto, le facilitará un espacio para que instale un rudimentario laboratorio en el que don Pio inicia su relación con las ciencias morfológicas microscópicas.

Terminada la licenciatura pasa don Pío a trabajar con el catedrático de Histologia, el profesor López García, que lo nombra profesor ayudante de clases practicas.

Mientras esto sucede a nivel local en el plano nacional se ha producido un hecho que va a tener profundas repercusiones en la vida de don Pío. En el año 1906 Ramón y Cajal recibe el premio Nóbel de Medicina. Este premio le convierte en un foco de atracción ineludible para todos los que se dedican al estudio microscópico ya en el terreno de la Histología o en el de Anatomía Patológica.

Don Pío siente, como otros muchos, esa atracción y busca los medios para poder trabajar al lado del Maestro. Una dificultad le sale inicialmente al paso: la incapacidad familiar para financiar su estancia en Madrid. Es por ello que donPio se ve forzado a intentarlo por otro camino: el de alcanzar una beca de la Junta para Ampliación de Estudios. Para lograr ese fin don Pio debe realizar varios viajes a la corte, cosa que su catedrático López Garcia encuentra poco habitual llegando a poner en conocimiento del decano las ausencias de su profesor de practicas. 
Leída su tesis doctoral, que versa sobre el estudio de los tumores cerebrales, don Pío consigue finalmente una de esas becas que le facilitan su estancia en Madrid y con ello poder trabajar con Cajal.

Hay que reconocer que la llegada de Río Hortega no fue acogida con satisfacción por el grupo de colaboradores más cercanos a Cajal. Como nos cuenta el propio don Pío en su libro El Maestro y yo pasó a trabajar en el laboratorio de Cajal en la Facultad de Medicina, en el edificio de San Carlos, en la calle Atocha, pero en un lugar bastante aislado del laboratorio.

En ese lugar Río Hortega trabaja según él mismo reconoce en el citado libro con acentuada dedicación y asistencia notable hasta tal punto que pese a las circunstancias se hace notar de Cajal que se dirige a él y le estimula en su trabajo en el que le orienta el Maestro. La importancia y relieve de don Pío va siendo con el paso de tiempo más significativa dentro del laboratorio de Cajal. Pero la fortuna adversa está al acecho y un incidente con Tomás el mozo de laboratorio lleva a que don Santiago tome una decisión excesiva: la separación de don Pío de su laboratorio. Una semana después Cajal reconoce su error y facilita que don Pío pase a trabajar con Nicolás Achúcarro, que dirige un modesto laboratorio que la Junta para Ampliación de Estudios ha montado en la Residencia de Estudiantes.

Nicolás Achúcarro es solo tres años mayor que Río Ortega, pero posibilitado por la situación económica de su familia ha conseguido tener ya un renombre muy importante tanto a nivel nacional con internacional. Ha trabajado en Alemania con las figuras más prestigiosas de Neuropatología como Alzheimer y ha sido designado por este como su discípulo más capacitado para dirigir el Centro de Enfermedades Mentales de Washington. Junto a tal bagaje cientifico Achúcarro suma el hablar correctamente varios idiomas, francés, alemán e inglés.

En el campo de las ciencias morfológicas uno de sus estudios de marcado relieve ha sido la descripción de las conexiones de la neuroglia de tipo fibroso con la pared de los capitales mediante unos apéndice que se denominan "las trompas de Achúcarro" en honor de su descubridor y que hoy desgraciadamente todos llamamos pies chupadores.

Junto Achúcarro, Pío Hortega va a completar lo que yo permito llamar siguiendo la nomenclatura que fijó Ortega y
Gasset como su etapa de "técnico artesano". En este periodo Río va a completar y perfeccionar al límite su capacidad para manejar y sacar el mayor poder de resolución a las diferente técnicas histológicas. Sirva como demostración de este aserto que don Pio se permite modificar la técnica que ha creado el propio Achúcarro y es conocida por la irregularidad absoluta que ofrece en sus resultados. Río, siguiendo lo que se hace en otras técnicas, incluye la acción de un mordiente, el camino, y variando la acción del óxido de plata y la acción reductora del formol estable cuatro variantes del método inicial que dan al investigador resultados seguros y capacidad de impregnar con ellas diferentes componentes tisulares tales como las fibras de colágeno a las reticulares y no los macrófagos. Podemos decir que don Pío es, en realidad, un virtuoso de la técnica histológica.

Siguiendo el esquema de Ortega y Gasset estamos autorizados a decidir que Río Hortega va ser capaz de desarrollar lo que Ortega denomina "La técnica del Técnico". Ha llegado el momento en Río va a poder crear su propio método para la investigación del mundo microscópico.

El paso que se va a producir en el modus operandi de Río es decisivo pero entraña uno de los misterios de la vida de nuestro maestro.

Técnicamente el paso es muy sencillo, consiste en sustituir el óxido de plata amoniacal, base de la gran mayoria de los métodos argentinos utilizados, por el carbonato de plata, que es su gran creación técnica. La gran pregunta es ¿qué es lo que lleva a Río Hortega a utilizar el carbonato de sodio para precipitar la solución de nitrato de plata?. Nadie ha sido capaz de encontrar respuesta aceptable para este hecho decisivo. ¿Fue una intuición? ¿Fue la utilización de error de preparación que decidió estudiar hasta sus últimas consecuencias? Insisto nadie ha podido responder a estas preguntas. Tampoco el propio Río nos facilito en sus, no numerosos escritos, una respuesta. Queda por ello como una gran incógnita.

Lo que sí conocemos perfectamente fueron las consecuencias del mismo. El nuevo método funcionó como una llave maestra que le permitió entrar en un mundo nuevo de la Anatomía microscópica.

Los estudios de diferentes autores, entre ellos de modo notable Cajal y Achúcarro habian establecido que en el sistema nervioso podian diferenciarse los siguientes compo-

ARBOR CLXXXI 714 JULIO-AGOSTO (2005) 203-206 ISSN: 0210-1963 
nentes: las neuronas o elementos conductores, la glía, en sus dos variantes de cortas y largas radiaciones y un elemento carente de prolongaciones al que Cajal denomina el tercer elemento de los centro nerviosos. Quedaba además por conocer el origen de las llamadas células en bastoncito.

El nuevo método de impregnación va a permitir a Río Hortega a resolver estas incógnitas de la estructura del tejido nervioso. Gracias a la capacidad resolutiva del carbonato de plata Río pone en evidencia que el denominado por Cajal "tercer elemento" o "células apolares" no es un elemento único y homogéneo. Según los trabajos de Río cabe diferenciar en ese tercer elemento dos variedades celulares diferentes: una que se localiza de preferencia en la sustancia gris de los centros y que por su tamaño denomina Microglia; y otro tipo celular que asienta de preferencia en la sustancia blanca en relación al parecer con los clindroejes o axones de las neuronas, y al que por las escasas prolongaciones que presenta denomina oligodendroglía.

La técnica ser revela además como es capaz de impregnar con nitidez algunos elementos del conectivo como los histiocitos y los fibroblastos.

Trabajos posteriores de Río ponen en evidencia que las células en bastoncillo corresponden a formas migratorias de la microglia que en sus trabajos se revelan de origen mesodérmico.

Los hallazgos de Río Hortega son, como era de esperar, recibidos en el mundo científico con cierto grado de desconfianza, pero en poco tiempo su realidad se impone. Esto lleva consigo que un desconocido investigador español pase a ocupar un puesto de relieve internacional.

Río Hortega es llamado por diferentes centros de Europa, Paris y Berlín entre otros, para que se desplace a sus universidades y centros de investigación y dé allí cursos sobre su técnica y sus hallazgos microscópicos. El estallido de la primera guerra mundial impide que Río pueda cumplir parte de esos compromisos.

Uno de los trabajos más importantes de Río en esos años es el que lleva por título "Tercera aportación para el conocimiento de la oligodendroglian. En él fija de un modo definitivo las caracteristicas morfológicas de estas célu- las y su relación con los axones neuronales. Río aporta otro dato más que es rechazado inicialmente por los discipulos de Cajal y es el referente a la similitud morfo-funcional entre las células de oligodendroglia de los centros nerviosos y las denominadas células de Schwann de los nervios periféricos. Río llega más allá de esa similitud morfológica y establece que ambos tipos celulares tienen que estar en relación con la formación o génesis de la mielina que rodea a las fibras nerviosas. Sólo años después de su desaparición los trabajos de diferentes autores de microscopía electrónica, como los de Robertson, revelaran de modo innegable la precisión de la hipótesis de Río.

Con sus trabajos Río Hortega se ha convertido en un figura de relieve nacional e internacional.

Tras dura oposición gana la dirección del "Centro Oncológico Nacional». Previamente había presidido en España la celebración de un Congreso Oncológico Internacional en el que presentó su ponencia la clasificación de los tumores de los centros nerviosos. Para esa calificación se apoyó en sus descubrimientos morfológicos anteriores.

Su fama internacional es de tal envergadura que es invitado a dar conferencias en las más prestigiosas universidades: asi visita Estados Unidos, Méjico, Cuba, Buenos Aires y países europeos como Francia, Bélgica y Alemania.

La guerra civil española rompe por completo su trayectoria vital. Como funcionario del Gobierno es desplazado a Valencia con un amplio grupo de profesores e intelectuales.

Parece necesario destacar en este momento dos acciones de Río. La primera su depósito en la caja fuerte del Banco de España de la dotación de radium que posee el Centro Oncológico Nacional a lo que añade los objetivos más valiosos de los microscopios de ese centro.

El segundo gesto conlleva la aparición de lo que yo denomino el segundo enigma de la vida de Río Hortega. En noviembre de 1936, cuando las tropas del general Franco parece que de un modo inmediato van a ocupar Madrid, Rio Hortega por medio de su sobrina Asunción y de su amigo Gómez del Moral consigue recuperar del Instituto Oncológico un número importante de preparaciones que guardaba en el mismo. Yo recuerdo como mi maestro don

ARBOR CLXXXI 714 JULIO-AGOSTO (2005) 203-206 ISSN: 0210-1963 
Fernando de Castro, discipulo notable de Cajal, guardaba con todo esmero y cuidado sus preparaciones más notables del corpúsculo carotideo o de sus experimentos de regeneración nerviosa.

Desconocemos que número de preparaciones se sacan del Instituto Oncológico. Solo conocemos que, según su sobrina Asunción, fueron varias cajas de zapatos las que se llenaron de preparaciones. Es dado suponer que estas preparaciones tenían para Río Hortega una significación y un valor inestimable. Por ello hay que suponer que al pasar a Valencia estas preparaciones viajaron con él a la ciudad levantina. Alli se pierden y pese a que las hemos buscado, nadie ha sabido darnos razón de ellas. Sería interesante que de un modo oficial se iniciara un estudio para tratar de conseguir su recuperación.

La evolución de la guerra determina que Río Hortega el trágico rumbo de la emigración. Se dirige primero a Francia trabajando con el neurocirujano $C$. Vincent pasando posteriormente a Inglaterra. Alli es llamado por diferentes instituciones de Canadá, Venezuela o Cuba. Mientras decide cual será su destino es proclamado "doctor Horis causa" por la universidad inglesa de Oxford.

Finalmente se decide don Pio por dar respuesta afirmativa a la petición que recibe desde Buenos Aires para que desarrolle un curso sobre sus trabajos y hallazgos. Aunque la propuesta es no muy segura en cuanto la estabilidad y su continuidad en el tiempo don Pío se decide por ella. Su recibimiento en el puerto argentino no se parece en nada al que se le dio en 1925.

Don Pio imparte su curso teórico-práctico y a su alrededor se forma un pequeño grupo de investigación argentino. Terminado el curso la angustiosa situación de don Pio se salva gracias a que la Institución Cultural Española, carente de relación con el gobierno español, le ofrece sus locales para instalar en ellos un laboratorio que permita a don Pío continuar sus trabajos de investigación en el sistema nervioso. En poco tiempo se pone en pie el laboratorio y don Pio ve surgir a su lado un grupo de investigadores argentinos. Con ellos va a realizar su última singladura investigadora centrada en el análisis de los denominados gliocitos o células satélites de los ganglios simpáticos. Poco tiempo antes un discipulo de don Pío había descrito un tipo celular semejante en los ganglios sensitivos de la raiz posterior de la médula espinal.

El grupo argentino dirigido por don Pío y con figuras relevantes como Moisés Polak emprende la publicación de una revista, Anales de Investigación Normal y Patológica, que pronto alcanza una alta estimación en el mundo de la investigación neurológica.

Es en las páginas de esa revista donde don Pío publica un artículo en el que presenta una nueva hipótesis.

El análisis de las preparaciones de los centros nerviosos pone de relieve que la neurona carece de relación directa con los vasos sanguíneos, lo que plantea la cuestión del modo en el que la neurona se nutre y se deshace de sus productos metabólicos. Las imágenes microscópicas revelan que la neurona está rodeada de la glia que constituye la que Castro denominó Atmósfera neuronal. Río Hortega emite ante esta situación lo que el denomina "angio-glío-neurona». Con ello quiere definir que la neurona sólo establece relaciones metabólicas con los vasos por medio de la glía. Este concepto de Río es, en este momento, un campo de estudio de los investigadores del sistema nervioso. Sus hallazgos parecen confirmar cada vez más y del modo más exacto y pleno la hipótesis de Río.

Otro campo que es hoy objeto de estudio y análisis es la relación de la oligodendroglía en la génesis de la mielina y la intervención de esta en la maduración de la fibra nerviosa y de su capacidad para llevar a término su actividad funcional.

El correr del tiempo va dejando en el pasado la figura de los hombres mientras que su obra sigue vigente y es objeto de estudio. Pero por ello, nosotros los castellanos tenemos que recordar a nuestro paisano que paseo el nombre Castilla por todo el mundo científico. 